\title{
In vitro and in vivo evaluation of antimicrobials in Escherichia coli infection in broilers and evaluation of ciprofloxacin in induced colibacillosis
}

\author{
Tanveer Ahmad ${ }^{1}$, Muhammad Fiaz $^{2}$, Aamir Sharif ${ }^{3 *}$, Muhammad \\ Nadeem $^{4}$, Sajjad-ur-Rehman ${ }^{5}$, Muhammad Rizwan ${ }^{6}$ and Muhammad \\ $\mathrm{Umer}^{7}$
}

1. Department of Clinical Sciences, Faculty of Veterinary Sciences, Bahauddin Zakariya University, Multan, Pakistan

2. Department of Veterinary Clinical Medicine and Surgery, University of Agriculture, Faisalabad, Pakistan

3. Government Poultry Farm, Bahawalpur, Livestock and Dairy Development Department, Punjab, District Bahawalpur, Pakistan

4. Pir Mehr Ali Shah Arid Agriculture University, Rawalpindi, Sub Campus Khushab, Pakistan

5. Institute of Microbiology, Faculty of Veterinary Sciences, University of Agriculture, Faisalabad, Pakistan

6. College of Veterinary Sciences, Bahadur Campus, Layyah, Bahauddin Zakariya University, Multan, Pakistan

7. Department of Animal Reproduction, Lasbela University of Water, Agriculture and Marine Sciences, Uthal,

Lasbela, Pakistan

*Corresponding author's email: aamirsharifcheema@ gmail.com

Citation

Tanveer Ahmad, Muhammad Fiaz, Aamir Sharif, Muhammad Nadeem, Sajjad-ur-Rehman, Muhammad Rizwan and Muhammad Umer. In vitro and in vivo evaluation of antimicrobials in Escherichia coli infection in broilers and evaluation of ciprofloxacin in induced colibacillosis. Pure and Applied Biology. Vol. 11, Issue 3, pp744-754. http://dx.doi.org/10.19045/bspab.2022.110075

\begin{tabular}{llll}
\hline \hline Received: 30/08/2021 & Revised: 06/09/2021 & Accepted: 09/11/2021 & Online First: 12/11/2021 \\
\hline
\end{tabular}

\section{Abstract}

The present study was conducted to 1) Survey and record the data regarding use of antimicrobials in Escherichia coli infection in broiler poultry flocks 2) Evaluate the sensitivity of E. coli against antibiotics and 3) Evaluate the ciprofloxacin in induced colibacillosis. For this purpose, fifty (50) broiler poultry farms were surveyed and in vitro evaluation of antimicrobials in E. coli infection was evaluated. The farmer level data regarding awareness about antibiotic usage pattern, storage of antibiotics, withdrawal period and antibiotic resistance was evaluated. Data revealed that most of broiler poultry farmers relied on quinolones (especially ciprofloxacin) to combat $E$. coli infection. The morbid samples from the E. coli infected farms were collected, pathogenicity of E. coli was checked and sensitivity against seven antibiotics viz. ciprofloxacin, enrofloxacin, gentamicin, oxytetracycline, colistin, neomycin and amoxycillin was evaluated. Sensitivity tests showed $E$. coli was highly sensitive against ciprofloxacin, enrofloxacin, and gentamicin. On the basis of antibiogram, the efficacy of ciprofloxacin was determined under in vivo conditions. Accordingly, 150 Hubbard (un-sexed) broiler chicks were divided into three groups viz. A, B \& C each having 50 chicks; group A was kept as uninfected and untreated (control), group B was experimentally infected and treated with ciprofloxacin while group C was infected and kept untreated. The mortality in group A, B and C was recorded as 2, $14 \& 28 \%$, respectively. The cumulative feed consumption in group $\mathrm{A}, \mathrm{B}$ and $\mathrm{C}$ was $84,87 \& 86 \mathrm{~kg}$ respectively. Mean weight gain in group A, B and C was $882.47,868.70 \& 801.29$ gm, respectively. The FCR in group A, B and C was 1.9, 2 and 2.15, respectively. It was concluded that the use of ciprofloxacin had high efficacy against $E$. coli infection in broiler chicks.

Keywords: Antimicrobials; Broilers; Ciprofloxacin; Escherichia coli 


\section{Introduction}

Poultry farming is one of the most profitable businesses in Pakistan. Poultry sector is the second largest industry in Pakistan after textile. It has emerged as a cheap and economical substitute for beef and mutton in Pakistan. Its importance can be judged from the fact that almost every family in rural areas and every fifth family in urban areas is associated with poultry production activities in one way or the other. The poultry industry has developed rapidly over the last three decades with an impressive growth rate of over $8 \%$ [1]. The development, expansion and intensification of poultry has faced problems of disease, nutrition and management. Colibacillosis caused by $E$. coli is a disease of economic concern in poultry industry [2-4]. E. coli is responsible for a variety of poultry diseases as it comprises of non-pathogenic and pathogenic strains that cause a number of diseases in host species including colibacillosis, colisepticemia, Hijar's disease, coligranuloma, peritonitis, salpingitis, synovitis, omphalitis and air sac disease [5]. E. coli is also responsible for high chick mortality, air saculitis, pericarditis and may predispose bird to adenovirus, reovirus, coronavirus and IBD virus and other secondary bacterial infection [6].

An incidence of $52 \%$ of colibacillosis is reported through isolation and identification of $E$. coli from trachea, lung, heart, blood, liver and spleen of poultry birds [7]. The prevalence of colibacillosis of $1 \%$ and $0.5 \%$ in $25-30$ days old and 3135 days old broilers, respectively is observed [8].

Antimicrobial therapy is an important tool in reducing the losses due to incidence and mortality associated with avian colibacillosis $[9,10,11]$. The fluoroquinolones are a class of antimicrobials that exhibit excellent activity against gramnegative organisms [12]. Among different fluoro-quinolones ciprofloxacin is of the potential interest for veterinary medicine. It has a wide antibacterial spectrum against mycoplasma, salmonella, E. coli, Haemophilus paragalinarum, Pasteurella multocida and staphylococcal infections in chicks $[13,14]$. Quinolones are bactericidal and act by inhibiting bacterial DNA replication and transcription. To facilitate coiling, winding and unwinding, the DNA gyrase allows the stands to be cut and reconnect. DNA gyrase, a topoisomerase, consists of $\mathrm{A}$ and $\mathrm{B}$ subunits. The most common target site for quinolones is the Asubunit of DNA gyrase coded by the gene gyrA. In Pakistan, the efficacy of this drug has not been evaluated. The present study was designed to determine in vitro and in vivo efficacy of ciprofloxacin in broiler chicks against $E$. coli.

\section{Materials and Methods}

\section{Survey for $E$. coli infected farms}

Fifty (50) broiler farms located in district Toba Tek Singh were visited for collection of data. Toba Tek Singh is located between $30^{\circ} 33^{\prime}$ to $31^{\circ} 2^{\prime}$ degree north latitudes and $72^{\circ} 08^{\prime}$ to $72^{\circ} 48^{\prime}$ degree longitudes. Data regarding drinking water, feeding, vaccination, disease-related morbidity, mortality and antibiotic usage, duration, efficacy, storage, brand, price and with drawl period were collected with an emphasis on E. coli infection. The efficacy of ciprofloxacin medication was determined.

\section{Isolation of $\boldsymbol{E}$. coli}

The livers and hearts of sick/dead chicks suffering from $E$. coli infection were collected. Samples were transported to the laboratory and processed as soon as possible for the isolation of E. coli. The MacConkey's agar medium, triple sugar iron agar medium and Simon's citrate medium were used for isolation, purification and identification of the organism [15]. The morphological, cultural staining characteristics, sugar fermentation, biochemical properties of isolates were determined. Biochemical tests were conducted according to recommended procedures [15-17]. 
Pathogenicity of $\boldsymbol{E}$. coli

A gut loop assay was performed for the determination of pathogenicity [18]. The rabbits were anaesthetized with ketamine $\mathrm{HCl}$ and ileum was exposed. $1 / 2 \mathrm{~mL}$ culture of the test isolate was delivered into the lumen of the intestine. An equal volume of normal saline was injected into the intestine of control rabbits. The cavity was sutured with catgut and animals were kept under extreme care and observations were recorded.

Antibiotic sensitivity of $\boldsymbol{E}$. coli

The susceptibility of pathogenic isolates to seven different antibiotics was determined using the disc diffusion method [19]. Mueller-Hinton agar was used for antibiotic susceptibility testing. Nutrient agar was incubated at $37^{\circ} \mathrm{C}$ for $15 \mathrm{hrs}$. The growth was diluted with normal saline to a density visually equal to $0.5 \mathrm{Mc}-$ Farland. Using a sterile swab, the bacterial suspension was spread in 3 different plates on MuellerHinton agar. The plates were dried at room temperature for 5 minutes. Seven commercially available antibiotic discs i.e. amoxicillin, gentamicin, ciprofloxacin, oxytetracycline, colistin, enrofloxacin and neomycin were placed on the agar plates using sterile forceps. The plates were incubated at $37^{\circ} \mathrm{C}$ for overnight. The radius of zone of inhibition of each antibiotic was measured using Schering antibiotic zone gauge and interpreted according to the zone size interpretative chart. Staphylococcus aureus ATCC 25923 (American Type Culture Collection) was used as a quality control organism. The resistant, intermediately susceptible and fully susceptible isolates to each antibiotic were measured and recorded (Table 1).

Table 1. Disc potencies of antibiotics, inhibition zone radius $(\mathrm{mm})$ to categorize $E$. coli and inhibition zone size of quality control organism (S. aureus ATTC 25923)

\begin{tabular}{|c|c|c|c|c|c|c|}
\hline \multirow{2}{*}{$\begin{array}{l}\text { Name of } \\
\text { Antibiotic }\end{array}$} & \multirow[b]{2}{*}{ Symbol } & \multirow{2}{*}{$\begin{array}{l}\text { Disc } \\
\text { Poten } \\
\text { cy } \\
(\mu \mathrm{g} / \\
\text { disc })\end{array}$} & \multicolumn{3}{|c|}{$\begin{array}{l}\text { Inhibition zone radius }(\mathrm{mm}) \text { to } \\
\text { categorize } E \text {. coli \& interpretation }\end{array}$} & \multirow{2}{*}{$\begin{array}{l}\text { Inhibition zone } \\
\text { size }(\mathbf{m m}) \text { of } \\
\text { quality control } \\
\text { organism } \\
\text { (S. aureus } \\
\text { ATTC } 25923)\end{array}$} \\
\hline & & & Susceptible & $\begin{array}{l}\text { Intermediat } \\
\mathrm{e}\end{array}$ & Resistant & \\
\hline Ciprofloxacin & Cip & 10 & $\geq 21$ & $16-20$ & $\leq 15$ & \\
\hline Enrofloxacin & Enr & 5 & $\geq 21$ & $16-20$ & $\leq 15$ & $20-24$ \\
\hline Gentamycin & $G$ & 10 & $\geq 15$ & 13-14 & $\leq 12$ & $19-27$ \\
\hline Colistin & Col & 25 & $\geq 16$ & $13-14$ & $\leq 13$ & $27-30$ \\
\hline $\begin{array}{l}\text { Oxytetracycli } \\
\text { ne }\end{array}$ & Oxy & 30 & $\geq 18$ & $13-15$ & $\leq 14$ & $12-15$ \\
\hline Amoxicillin & $\mathrm{Am}$ & 25 & $\geq 18$ & $14-17$ & $\leq 13$ & $28-36$ \\
\hline Neomycin & $\mathrm{N}$ & 25 & $\geq 17$ & $13-16$ & $\leq 12$ & $18-26$ \\
\hline
\end{tabular}

National Committee for Clinical Laboratory Standards (NCCL, 1990)

\section{Test culture}

A pathogenic isolate of E. coli was inoculated into the fresh nutrient broth and incubated at $37^{\circ} \mathrm{C}$ for overnight. The viable bacteria were counted [15]. The broth was diluted with phosphate buffer saline (PBS) to have approximately $1 \times 10^{6} \mathrm{CFU}$ organisms / $\mathrm{mL}$, which was used for experimental infection.
Evaluation of ciprofloxacin in induced $E$. coli infection

For evaluation of ciprofloxacin in induced E. coli infection one hundred and fifty (150) day-old Hubbard (un-sexed) broiler chicks were reared under uniform conditions of management and nutrition at department of Veterinary Clinical Medicine and Surgery, University of Agriculture, Faisalabad. All chicks were vaccinated against Newcastle 
disease, Infectious bursal disease (IBD / Gumboro) and Hydropericardium syndrome (Table 2). At $20^{\text {th }}$ day of age, chicks were randomly divided into three equal groups viz. A, B and C. $1 \mathrm{~mL}$ of diluted broth culture of a pathogenic strain of E. coli $\left(1 \times 10^{6} \mathrm{CFU}\right.$ organisms / $\left.\mathrm{mL}\right)$ was inoculated orally with the help of the crop tube to the chicks of group B and C, while the chicks of group A were kept as control (uninfected \& untreated). All the chicks were kept under observation for development of clinical signs and symptoms for 2 weeks. After the appearance of clinical signs (dullness, depression, vent pasting, respiratory and enteric signs) and postmortem lesions (pericarditis, perihepatitis and air sacculitis), the chicks of group B were treated with ciprofloxacin 20\%@1 ml / 4L $\left(\right.$ Ciprosel $\left.^{\circledR}\right)$ PO as recommended by the manufacturer for 5 days. Chicks in group $\mathrm{C}$ were challenged and untreated control, while group A was control (unchallenged and untreated) (Table 3).

Table 2. Vaccination schedule of experimental chicks

\begin{tabular}{|c|c|c|}
\hline Age (Days) & Vaccine & Route \\
\hline 4 & ND $\left(1^{\text {st }}\right.$ dose $)$ & E/D \\
\hline 9 & Gumboro $\left(1^{\text {st }}\right.$ dose $)$ & E/D \\
\hline 15 & Hydropericardium Syndrome & S/C \\
\hline 19 & Gumboro $\left(2^{\text {nd }} d o s e\right)$ & D/W \\
\hline 23 & ND $\left(2^{\text {nd }}\right.$ dose $)$ & D/W \\
\hline
\end{tabular}

E/D Eye drop; S/C Sub-cutaneous; D/W Drinking water

Table 3. Different treatments in experimental groups

\begin{tabular}{|c|c|c|c|}
\hline Treatments & Group A & Group B & Group C \\
\hline No. of chicks & 50 & 50 & 50 \\
\hline Quantity of inoculums & $1 \mathrm{~mL}$ & $1 \mathrm{~mL}$ & $1 \mathrm{~mL}$ \\
\hline Concentration of inoculums & - & $1 \times 10^{6} \mathrm{CFU} / \mathrm{bird}$ & $1 \times 10^{6} \mathrm{CFU} / \mathrm{bird}$ \\
\hline Antibiotic usage & - & Single & - \\
\hline Treatment (Antibiotic usage) & - & Ciproflaxocin $20 \%$ & - \\
\hline Concentration of drug & - & $20 \mathrm{gm} / 100 \mathrm{~mL}$ & - \\
\hline Dose rate (@) & - & $1 \mathrm{~mL} / 4 \mathrm{~L}$ & - \\
\hline Route of Treatment & - & Oral / Drinking & - \\
\hline Name of Brand & - & Water & - \\
\hline Duration of Treatment (Days) & 5 & 5 & 5 \\
\hline
\end{tabular}

\section{Parameters of the efficacy of treatment}

Parameters of mortality, cumulative feed consumption, mean body weight and feed conversion ratio were observed in experimental groups for the determination of drug efficacy.

\section{Statistical analysis}

Data was statistically analyzed / compared accordingly.

\section{Results and Discussion}

Avian colibacillosis is one of the major endemic diseases affecting poultry industry worldwide [3] and is main cause of economic losses [2]. Avian pathogenic $E$. coli (APEC) causes extensive mortality in poultry flocks [4] and may pose a human health risk [2].

Fluoro-quinolone is a group of bactericidal antibiotics, has large volume of distribution, wide spectrum of activity and favourable margin of safety. No plasmid related resistance is reported $[20,21]$. Several members of this group i.e. flumequine, norfloxacin, ciprofloxacin, 
enrofloxacin are used in poultry for the treatment of different infections [14, 22, 23]. Ciprofloxacin was mainly developed for veterinary use against mycoplasmosis and colibacillosis.
Survey report regarding treatment of $E$. coli infection in broiler birds is shown in (Table 4). Frequency distribution (range of poultry farmers) of awareness about antimicrobial therapy is shown in (Table 5).

Table 4. Survey for the treatment of $E$. coli infections

\begin{tabular}{|c|c|c|c|c|c|}
\hline \multirow[b]{2}{*}{$\begin{array}{l}\text { Flock } \\
\text { size }\end{array}$} & \multicolumn{2}{|c|}{ Mortality } & \multirow{2}{*}{$\begin{array}{c}\text { E. coli infection } \\
\text { (Primary / secondary) }\end{array}$} & \multirow[b]{2}{*}{$\begin{array}{l}\text { Percent } \\
\text { reduction }\end{array}$} & \multirow[b]{2}{*}{ Medication } \\
\hline & $\begin{array}{c}\text { Pre- } \\
\text { treatment }\end{array}$ & $\begin{array}{c}\text { Post- } \\
\text { treatment }\end{array}$ & & & \\
\hline 3200 & 300 & 65 & Secondary & 7.34 & Ciprosel \\
\hline 3000 & 140 & 25 & -do- & 3.83 & VetyEnrox 20\% \\
\hline 2000 & 50 & 15 & -do- & 1.75 & Atiquine $20 \%$ \\
\hline 2500 & 200 & 120 & -do- & 3.2 & VetyEnrox 20\% \\
\hline 3800 & 296 & 90 & -do- & 5.43 & Ciprosel \\
\hline 3500 & 450 & 125 & -do- & 11.28 & Ciprosel \\
\hline 2000 & 158 & 80 & -do- & 3.25 & Flumiquine $20 \%$ \\
\hline 2800 & 390 & 127 & -do- & 9.39 & Tribrissen + CTC $20 \%$ \\
\hline 5000 & 305 & 90 & -do- & 4.43 & Flumesol $50 \%$ \\
\hline 2500 & 400 & 290 & -do- & 4.4 & Colisol powder \\
\hline 2800 & 510 & 235 & -do- & 9.82 & Ciprosel \\
\hline 10000 & 250 & 52 & - do- & 2 & Floxamycin \\
\hline 4000 & 398 & 85 & -do- & 7.85 & Enrosol S + Colimycin \\
\hline 2200 & 290 & 108 & -do- & 8.27 & Ciprosel \\
\hline 4000 & 311 & 105 & -do- & 5.15 & Ciprosel \\
\hline 2500 & 205 & 180 & -do- & 5.46 & Tribrissen \\
\hline 3200 & 320 & 100 & -do- & 6.87 & Ciprosel \\
\hline 2500 & 150 & 69 & -do- & 3.24 & Floxamycin \\
\hline 5500 & 450 & 125 & - do- & 5.90 & Enrosol S \\
\hline 3100 & 220 & 105 & -do- & 3.7 & Atiquine $20 \%$ \\
\hline 6000 & 440 & 135 & - do- & 5.08 & VetyEnrox $10 \%$ \\
\hline 2900 & 297 & 85 & -do- & 7.41 & Ciprosel \\
\hline 3000 & 189 & 50 & -do- & 4.63 & Oramox Plus \\
\hline 3000 & 120 & 18 & -do- & 3.34 & TylanSolube \\
\hline 4000 & 250 & 20 & -do- & 5.75 & Norflox $20 \%$ \\
\hline 2700 & 185 & 130 & -do- & 2.03 & Atiquine $20 \%$ \\
\hline 7500 & 492 & 90 & -do- & 5.36 & Quintox \\
\hline 4200 & 435 & 80 & -do- & 8.45 & Ciprosel \\
\hline 3500 & 320 & 100 & -do- & 6.28 & Norflox $20 \%$ \\
\hline 2700 & 189 & 50 & -do- & 5.14 & Enrosol S \\
\hline 2200 & 140 & 32 & -do- & 4.90 & Tribrissen \\
\hline 4500 & 312 & 95 & -do- & 4.82 & Colisole powder \\
\hline 2800 & 142 & 63 & -do- & 2.82 & Oxytet \\
\hline 1500 & 90 & 33 & Primary & 3.80 & Oxytet + colimycine \\
\hline 3000 & 110 & 45 & Secondary & 2.16 & Ateuine-P 50 \\
\hline 3500 & 319 & 115 & -do- & 5.82 & Ciprosel \\
\hline 1800 & 120 & 55 & -do- & 3.61 & Oramox Plus \\
\hline
\end{tabular}




\begin{tabular}{|l|c|c|l|c|c|}
\hline 2000 & 115 & 43 & -do- & 3.60 & Tylan Soluble \\
\hline 2500 & 297 & 87 & - do- & 8.40 & Ciprosel \\
\hline 3200 & 180 & 65 & - do- & 3.59 & Floxamycin \\
\hline 3500 & 315 & 125 & - do- & 5.42 & Ciprosel \\
\hline 4000 & 365 & 138 & - do- & 5.67 & Ciprosel \\
\hline 1400 & 70 & 25 & - do- & 3.21 & Tribrissen \\
\hline 1000 & 32 & 8 & - do- & 2.40 & Neomycin Sulphate \\
\hline 1200 & 28 & 6 & - do- & 1.83 & Flumesol \\
\hline 1800 & 44 & 13 & - do- & 1.72 & Flumesol \\
\hline 3200 & 115 & 42 & - do- & 2.28 & Oxytet \\
\hline 1700 & 72 & 25 & - do- & 2.76 & Colisol + Oxytet \\
\hline 2000 & 110 & 45 & - do- & 3.25 & Oramox Plus \\
\hline 5200 & 415 & 120 & - do- & 5.67 & Enrosol S \\
\hline
\end{tabular}

Table 5. Frequency distribution (range of poultry farmers) of awareness about antimicrobial therapy

\begin{tabular}{|c|c|c|}
\hline \multicolumn{2}{|c|}{ Parameters } & Range of poultry farmers \\
\hline \multirow{3}{*}{ Antimicrobial source } & Distributor & $36-40$ \\
\cline { 2 - 3 } & Veterinary medical store & $0-5$ \\
\cline { 2 - 3 } Prescriber of antimicrobial therapy & Other & $0-5$ \\
\hline \multicolumn{2}{|c|}{ Distributor } & $31-35$ \\
\cline { 2 - 3 } & Self & $0-5$ \\
\cline { 2 - 3 } & Veterinarian & $6-10$ \\
\hline Withdrawal period & $16-20$ \\
\hline Price of antibiotic & $0-5$ \\
\hline Proper storage at farm & $36-40$ \\
\hline In-effectiveness of antimicrobials (particular antibiotic) & $0-5$ \\
\hline Resistance to antimicrobials & $6-10$ \\
\hline Irrational use & $0-5$ \\
\hline
\end{tabular}

In vitro characteristics of $E$. coli isolates

In our study the morphological and biochemical characteristics were observed for isolation and identification of $E$. coli isolate. After $24 \mathrm{hrs}$ of incubation at $37^{\circ} \mathrm{C}$ on MacConkey's agar all E. coli isolates developed pink, pin pointed colonies, having luxuriant growth and colony size varied from $2-3 \mathrm{~mm}$ in diameter. The isolates were cocco-bacillary, long filamentous, gram-negative, non-spore forming and motile. On the basis of triple sugar iron agar reaction, the isolates fermented lactose and sucrose with the production of gas. The isolates on Simon's citrate medium changed the colour from green to blue.

Biochemical reactions of $E$. coli isolates included lactose and sucrose fermentation with the production of gas, but non- production of hydrogen sulphide. On Simon's citrate medium, the isolates changed the colour of the medium from original green to blue. Other researchers also observed the bio-chemical characteristics of $E$. coli strains with same method $[18,26]$. The microscopic, cultural and morphological characteristics of $E$. coli of present study were in-consistent with results of previous studies [24, 25, 27].

In vitro antibiotic susceptibility of $E$. coli isolates

Antibiotic susceptibility profiles of $E$. coli indicated ciprofloxacin and enrofloxacin were $100 \%$ effective, while effectiveness of gentamicin, neomycin, colistin, oxytetracycline and amoxicillin were 83, $69,62,55$ and $45 \%$, respectively (Table 6). Previously sensitivity of $83.08 \%$ to both ciprofloxacin and Enrofloxacin against $E$. 
coli is noticed [28]. The high sensitivity of $100 \%$ of $E$. coli to ciprofloxacin is also recorded [24].

The use of antibiotics and other drugs for the control and treatment of colisepticemia helps to avoid economic losses from the disease. Most of the E. coli strains are normally sensitive to most of the antibiotics and chemo-therapeutic agents but in recent years' resistance has been encountered in many cases. Therefore, it is advisable to perform an antibiotic sensitivity test to minimize the hazards of drug resistance and to avoid economic losses on treatment [29]. In the present study the antibiotic sensitivity test of E. coli isolates was performed using seven antimicrobial agents. The E. coli isolates were most sensitive to ciprofloxacin and enrofloxacin followed by gentamycin and Colistin and resistant to amoxicillin, neomycin, and oxytetracycline. In other studies, the antibiotic sensitivity of $E$. coli isolates against flumequine was most effective [30]. Isolates having septicemia have also shown sensitivity to nalidixic acid [31]. Less susceptibility E. coli against antibiotics has also been recorded [29, 32, 33]. It is also reported that $E$. coli of poultry are resistant to one or more antibiotics. It is advisable to determine the drug sensitivity of the strains of E. coli involved in the diseased condition. Researchers have reported susceptibility and resistance of E. coli strains to various antibacterial agents [3336]. The variance in drug susceptibility might be due to prevalent serotypes and frequent use of antibacterial in the feed or drinking water. In our study disc diffusion test was used to determine susceptibility to antibiotics. The disc diffusion method is also used for antibiotic susceptibility profiles, resistance and multiple drug resistance to $E$. coli by other researchers $[24,37]$.

There is widespread antimicrobial resistance to avian pathogenic $E$. coli (APEC) [38]. Also, there is emerging drug resistance to $E$. coli associated with colibacillosis [24]. Studies on antibiogram profile of $E$. coli isolate of chicken showed that it is also multidrug resistant [8]. Resistance to APEC isolates against antimicrobials has increased over time and further improvements in treatment guidelines against bacterial pathogens of poultry are required [39]. Resistance of $30.55 \%$ of $E$. coli to ciprofloxacin is reported [40]. The resistance of $46.8 \%$ of APEC isolates to ciprofloxacin is reported due to the carrying of resistance genes [4]. $72 \%$ antimicrobial resistance [41] and further higher antimicrobial resistance of $87 \%$ against ciprofloxacin is also reported [42]. The reason for multidrug resistance in APEC may be due to the heavy usage of antibiotics for the treatment of diseases in poultry flocks [42]. The other significant risk factor associated with the presence of multiple drug resistant (MDR) APEC is the use of ground water and closely located poultry farms [38]. As E. coli are part of normal flora of birds, the prevention and control of colibacillosis can be challenging [43]. The antibiogram profile of the E. coli isolate can help in therapeutic decisionmaking in the treatment of colibacillosis [25].

Table 6. In vitro susceptibility of $E$. coli to antibiotics

\begin{tabular}{|c|c|c|c|c|}
\hline \multirow{2}{*}{ Antibiotics } & \multirow{2}{*}{ No. of samples } & \multicolumn{3}{|c|}{ Susceptibility (\%) } \\
\cline { 3 - 5 } & & Susceptible & Intermediate & Resistant \\
\hline Ciprofloxacin & 100 & 100 & - & - \\
\hline Enrofloxacin & 100 & 100 & - & - \\
\hline Gentamycin & 100 & 83 & - & 17 \\
\hline Neomycin & 100 & 69 & - & 31 \\
\hline Colistin & 100 & 62 & 11 & 27 \\
\hline Oxytetracyclin & 100 & 55 & 15 & 30 \\
\hline Amoxycillin & 100 & 45 & - & 55 \\
\hline
\end{tabular}




\section{Pathogenicity of $E$. coli}

In nutrient broth $E$. coli isolates produced slight pellicle formation at $18-24 \mathrm{hrs}$ with a slimy deposit at the bottom of the tube which on shaking produced a uniform turbidity. The identified culture of $E$. coli was tested by gut loop ligation method for pathogenicity of the strain. In the positive cases intestinal part became triple size as compared to the normal. The fluid accumulation in intestine indicated positive results, whereas, absence of fluid accumulation indicated negative results. Along with the presence of fluid, the amount of the fluid also served as an indicator of positive results. The higher the amount of fluid observed, the higher the pathogenic strain of E. coli it represents. The culture that showed maximum pathogenicity was selected for induced $E$. coli infection. The control sample was inoculated with normal saline instead of $E$. coli. In the present study intestinal loop ligation method positive (i.e., pathogenic) E. coli were identified by increased size (i. e triple fold than normal) and increased luminal fluid of the intestine, which coincide with the results of previous studies $[18,23,26]$.

In vivo efficacy of ciprofloxacin in induced $E$. coli infection

In our study the artificial infection of colibacillosis was done using pathogenic isolate of E. coli which was inoculated @ 1 $\times 10^{6} \mathrm{CFU}$ organisms / mL through oral route in group $\mathrm{B}$ and $\mathrm{C}$. The chicks were kept under observation for further two week. While in other studies the chicks were artificially infected with $3 \times 10^{8} \mathrm{CFU} /$ $0.25 \mathrm{~mL}$ of entero-toxigenic E. coli (ETEC) through intra-peritoneal route and infection developed within twelve hours [44]. In our study the chicks of group B were treated with ciprofloxacin 20\% @ $1 \mathrm{ml} /$ 4L $\left(\right.$ Ciprosel $^{\circledR}$ ) PO as recommended by the manufacturer for 5 days. Chicks in group $\mathrm{C}$ were challenged and untreated control, while group A was control (unchallenged and untreated)
Previously the efficacy of quinolones on $E$. coli, salmonella and mycoplasma infection had also been evaluated $[45,46]$. In the present study, chicks that manifested clinical signs of colibacillosis were treated with Ciprosel ${ }^{\circledR}$ (ciprofloxacin 20\%) for 5 days at the dose of $1 \mathrm{~mL} / 4 \mathrm{~L} \mathrm{DW}$. The results of present study are in agreement with previous findings. The high in vitro and in vivo efficacy of ciprofloxacin may be attributed to its wide spectrum activity, large volume of distribution and high efficacy rate against $E$. coli, thus resulting in increased introduction for field use [20]. No plasmid resistance has been demonstrated and they have a factorable margin of safety [21]. The findings of high efficacy of ciprofloxacin in E. coli infection has also been previously reported $[32,33$, $45,46]$.

\section{Mortality post-treatment}

The mortality in group A, B and C was 1, 7 and 14 chicks, respectively after treatment (Table 7).

\section{Postmortem findings}

The post-mortem examination of chicks died in different experimental groups was performed. Thickened and cloudy air sacs were observed. In severe cases, caseous exudates on air sacs were present. Adhesive pericarditis and fibrinous perihepatitis were present in most of the cases. Enteritis along with excessive mucus was common. The primary lesions of colisepticemia were pericarditis, perihepatitis and air sacculitis were observed. Pericardial fluid became progressively more fibrinous. Necrotic foci in the heart muscles were present in chicks that succumbed to infection. The pericardial sac was thickened with pale-colored gelatinous exudates. Congestion of liver, spleen, kidney and small intestine were also observed. Similar findings were also observed in previous studies [14, 23].

The cumulative feed consumption, per bird feed consumption, mean body weight of chick sand FCR in each group is presented in (Table 8). FCR of broiler chicks kept in the group A, B, and C were 1.90, 2.00 and 2.15 respectively. FCR increased in group 
C because chicks in this group were infected with $E$. coli but were not treated.

Table 7. Post inoculation mortality pattern in groups

\begin{tabular}{|c|c|c|c|c|c|}
\hline \multirow{2}{*}{ Age (days) } & \multirow{2}{*}{$\begin{array}{c}\text { Day post inoculation } \\
\text { (DPI) }\end{array}$} & \multicolumn{3}{|c|}{ Mortality } & \multirow{2}{*}{ Total } \\
\hline & & $\mathbf{A}$ & B & $\mathbf{C}$ & \\
\hline $21^{\mathrm{st}}$ & $1^{\mathrm{st}}$ & - & 4 & 4 & 8 \\
\hline $22^{\text {nd }}$ & $2^{\text {nd }}$ & - & 2 & 4 & 6 \\
\hline $23^{\text {rd }}$ & $3^{\text {rd }}$ & - & 1 & 3 & 4 \\
\hline $24^{\text {th }}$ & $4^{\text {th }}$ & - & - & 1 & 1 \\
\hline $25^{\text {th }}$ & $5^{\text {th }}$ & - & - & 1 & 1 \\
\hline $26^{\text {th }}$ & $6^{\text {th }}$ & - & - & - & - \\
\hline $27^{\text {th }}$ & $7^{\text {th }}$ & - & - & - & - \\
\hline $28^{\text {th }}$ & $8^{\text {th }}$ & - & - & - & - \\
\hline $29^{\text {th }}$ & $9^{\text {th }}$ & 1 & - & 1 & 2 \\
\hline \multicolumn{2}{|r|}{ Total $=$} & 1 & 7 & 14 & 22 \\
\hline \multicolumn{2}{|c|}{ Percentage $(\%)=$} & 2 & 14 & 28 & 44 \\
\hline
\end{tabular}

Table 8. Cumulative feed consumption, per bird feed consumption, mean body weight of chicks and FCR in groups

\begin{tabular}{|c|c|c|c|c|c|c|c|c|c|c|c|c|}
\hline \multirow{2}{*}{$\begin{array}{c}\text { Age } \\
\text { (da }\end{array}$} & \multicolumn{3}{|c|}{$\begin{array}{c}\text { Total feed } \\
\text { consumption }\end{array}$} & \multicolumn{2}{c|}{$\begin{array}{c}\text { Feed consumption } \\
\text { (kg) per bird }\end{array}$} & \multicolumn{3}{c|}{ Mean body weight } & \multicolumn{3}{|c|}{$\begin{array}{c}\text { Feed conversion } \\
\text { ratio }\end{array}$} \\
\cline { 2 - 13 } \\
$\mathbf{y s )}$ & $\mathbf{A}$ & $\mathbf{B}$ & $\mathbf{C}$ & $\mathbf{A}$ & $\mathbf{B}$ & $\mathbf{C}$ & $\mathbf{A}$ & $\mathbf{B}$ & $\mathbf{C}$ & $\mathbf{A}$ & $\mathbf{B}$ & $\mathbf{C}$ \\
\hline $17^{\text {th }}$ & 23 & 23.50 & 23 & 0.46 & 0.47 & 0.46 & 282.29 & 288.58 & 284.94 & 1.63 & 1.63 & 1.63 \\
\hline $23^{\text {rd }}$ & 37 & 37 & 36.5 & 0.74 & 0.74 & 0.73 & 423.41 & 420.17 & 409.64 & 1.75 & 1.76 & 1.79 \\
\hline $26^{\text {th }}$ & 42 & 42.50 & 42.5 & 0.84 & 0.85 & 0.85 & 460.11 & 464.29 & 436.17 & 1.82 & 1.83 & 1.95 \\
\hline $31^{\text {st }}$ & 84 & 87 & 86 & 1.68 & 1.74 & 1.72 & 882.47 & 868.70 & 801.29 & 1.90 & 2.00 & 2.15 \\
\hline
\end{tabular}

\section{Conclusion}

Use of ciprofloxacin in E. coli infection decreased mortality, increased feed consumption, increased body weight and increased FCR in broiler flocks. It was concluded that ciprofloxacin demonstrated very high efficacy against avian $E$. coli infection

\section{Authors' contributions}

Conceived and designed the experiments: $\mathrm{T}$ Ahmad, Performed the experiments: $M$ Fiaz, Analyzed the data: T Ahmad, M Fiaz \& A Sharif, Contributed materials/ analysis/tools: M Nadeem, SU Rehman, M Rizwan \& M Umer, Wrote the paper: T Ahmad, M Fiaz, A Sharif \& M Nadeem.

\section{References}

1. GoP, (2020). Economic Survey of Pakistan, Economic Advisory Wing, Finance Division, Islamabad, Pakistan.

2. Vounba P, Y Kane, C Ndiaye, J Arsenault, JM Fairbrother \& Alambedji RB (2018).
Molecular characterization of Escherichia coli isolated from chickens with colibacillosis in Senegal. Foodborne Pathog Dis 15: 8.

3. Panth Y (2019). Colibacillosis in poultry: A review. J Agri Nat Res 2(1): 301-311.

4. Kim YB, MY Yoon, JS Ha, KW Seo, EB Noh, SH Son and Lee YJ (2020). Molecular characterization of avian pathogenic Escherichia coli from broiler chickens with colibacillosis. Poult Sci 99: 1088-1095.

5. Dozois CM, F Daigle \& Curtiss R (2003). Identification of pathogen-specific and conserved genes expressed in vivo by and avian pathogenic Escherichia coli strain. Proc Natl Acad Sci USA 100: 247-52.

6. Kim JY, Kim SH, Kwon NH, Bae WK, Lim JY, Koo HC, Kim JM, Noh KM, Jung WK, Park KT \& Park YH (2005). Isolation and identification of Escherichia coli O157:H7 using different detection methods and molecular determination by multiplex PCR and RAPD. $J$ Vet Sci 6: 7-19. 
7. Tawab AAAE, Ammar AM, EI-Hofy FI, Hakeem MA \& Galil NMA (2016). Preliminary studies on E. coli implicated in colibacillosis with reference to their antibiotic resistance profiles. Benha Vet Med J 30(1): 68-77.

8. Matin MA, Islam MA \& Khatun MM (2017). Prevalence of colibacillosis in chickens in greater Mymensingh district of Bangladesh. Vet World 10(1): 29-33.

9. Freed M, Clarke JP, Browersock TL, Alstine WGV, Balong JM \& Hester PY (1993). Effect of spectinomycine on Escherichia coli infection in day old ducklings. Avian Dis 37: 763-766.

10. Goren E (1990). Colibacillose bij pluimvee: etiologic en therapic. Pluimvee symposium. Upjohn, Doorn, Neterland 160-185.

11. Watts JL, Salmon SA, Yancy RJ, Nersessian B \& Kouney ZV (1993). Minimum inhibitory concentration of bacteria isolated from septicemia and air sacculitis in ducks. J Vet Diag Invest 5: 625-628.

12. Raemdonck DL, Tanner AC, Tolling ST \& Michener SL (1992). In vivo susceptibility of avian Escherichia coli and Pasturella multocida to enrofloxacin and five other antimicrobials. Avian Dis 36: 964-967.

13. Anadon A, Larrañaga MRM , Díaz MJ , Bringas P , Martínez MA , Cruz MLF, Fernández MC \& Fernández R (1995). Pharmacokinetics and residues of enrofloxacin in chickens. Am J Vet Res 56: 501-505.

14. Saleem M, Muhammad G, Siddique M \& Zia T (1999). In vitro antibiotic susceptibility profiles of avian Escherichia coli in and around Faisalabad. Pak Vet J 19: 139-141.

15. Cruickshank R (1975). Medical microbiology: the practice of medical microbiology. 12 $2^{\text {th }}$ Ed. The English Language Book Society and E. Livingstone, London, UK. pp: 211-215.

16. Cottral EG (1978). Manual of standardized methods for veterinary microbiology. Cornstock Pub Assoc Ithaca USA pp: 5056.

17. Cheesbrough M (1991). Medical laboratory manual for tropical countries. Vol. II. Tropical Health Technology, Doddington, England, Butter-worth (Publishers) Ltd. London.
18. Altwegg M \& Bochkemiki J (1998). Escherichia and Shigella In: Topeland Wilson's Microbiology and Microbial infections. Eds. $9^{\text {th }}$, vol. 2, Arnold, London, pp: 946-947.

19. NCCL (1990). Performance standard for antimicrobial disc susceptibility test. $4^{\text {th }}$ Eds. Approved Standard M2-A3. National Committee for Clinical Laboratory Standards, Villanova Pa. USA.

20. Vancutsem PM, Babish JB \& Schwark WS (1990). The fluoroquinolone antimicrobials, structure antimicrobial activity, pharmacokinetics, clinical use in domestic animals and toxicity. Cornell Vet 80: 173-186.

21. Bahri EL \& Blouin A (1991). Fluoroquinolones, a new family of antimicrobials. Compendium Cont Edu Pract Vet 13: 1429-33.

22. Brazile-Pham KS, Quechi T, Lafont JP \& Gutmann L (1996). Resistance to fluoroquinolones in Escherichia coli isolates from poultry. Antimicrob Agent Chem 40: 1504-1507.

23. Ahmad T, Muhammad G, Sharif A, Nadeem M, Shakoor A \& Rizwan M (2020). Survey of antibiotic treatment of Escherichia coli infection in broilers and efficacy of enrofloxacin plus colistin in experimental colibacillosis. Pure Appl Biol 9(3): 1864-1872.

24. Saidi B, Mafirakureva P \& Mbanga J (2012). Antimicrobial resistance of Escherichia coli isolated form chickens with colibacillosis in and around Harare, Zimbabwe. Avian Diseases 57(1): 152-154.

25. Rahman MA, Rahman AKMA, Islam MA \& Alam MM (2017). Antimicrobial Resistance of Escherichia coli Isolated From Milk, Beef and Chickens Meat in Bangladesh. Bangl J Vet Med 15(2): 141146.

26. Akhtar M, Ashfaqe M, Afzal H \& Aqaf M (1991). Comparison of congo red and biochemical tests in differentiating enteropathgenic Esherichia coli. J Amin Plant Sci 1: 63-66.

27. Merchant LA \& Packer RA (1971). Veterinary bacteriology and virology. $7^{\text {th }}$ ed. Iowa State Univ. Press, Ames, Iowa, USA. pp: 332-341.

28. Sharada R, Ruban S \& Thiyageeswaran M (2008). Antibiotic resistance pattern of 
Escherichia coli isolated from poultry in Bangalore. Internet J Microbiol 7(1): 1-5.

29. Pandey GS, Tuchili LM, Kaneuchi C, Wulaya \& Nyeleti G (1998). Studies on avian colibacillosis outbreak and drug sensitivity of E. coli isolates in Lusaka, Zambia. Ind Vet J 75: 754-755.

30. Haneef, W \& Siddique M (1990). Prevalence and antibiogram of Escherichia coli isolates in and around Faisalabad. Proc $3^{\text {rd }}$ Intl Cong Pak Vet Med Assoc 285-292.

31. Krishnamohan RY, Shoba K, Dorairajan N \& Punninamurthy $\mathrm{N}$ (1995). In vivo sensitivity studies of Escherichia coli to quinolones. Ind Vet J 72: 752-53.

32. Ibrahim AI, Elattar AA \& EI-Shahidy MS (1997). Studies on E. coli isolates from respiratory affected broiler and protection evaluation of different prepared bacterians. Assiut. Vet Med J 37: 152-162.

33. Prasad V, Murthy KK \& Rao TVJ (1997). In vivo antibiogram studies of Escherichia coli in chickens. Ind Vet $J$ 74: 616-617.

34. Babila A \& Akcadag B (1992). Drug sensitivity and biochemical and serological characteristics of Escherichia coli strains isolate from broiler in the Marmara region. Hag van Hastaliklari Merker 23: 37-50.

35. Kaul L, Kauln PL \& Shah NM (1992). An outbreak of colibacillosis in broiler chicks at an organized poultry farm under semiarid zone in North Gujrat. Ind Vet J 69: 373374.

36. Hameed A, F Hasan, T Javed \& Azam M (1995). Resistance of enteropothogenic Escherichia coli to traditional and third generation antibacterials. Pak J Livest Poult 1: 84-88.

37. Kuznetsova MV, Gizatullina JS, Nesterova LY \& Erjaves MS (2020). Escherichia coli isolated from cases of colibacillosis in Russian poultry farms (Perm Krai): sensitivity to antibiotics and bacteriocins. Microorganisms 8: 741.

38. Ibrahim RA, Cryer TL, Lafi SQ, Ehab-Abu Basha, Good L \& Tarazi YH (2019). Identification of Escherichia coli from broiler chickens in Jordan, their antimicrobial resistance, gene characterization and the associated risk factors. BMC Vet Res 15:159.

39. Nhung NT, Chansiripornchai N \& Carrique-Mas JJ (2017). Antimicrobial resistance in bacterial poultry pathogens: A Review. Front Vet Sci 4: 126.

40. Hossain MA, Amin MR, Khan MDI, Mollah ML \& Amin MA (2015). Occurrences, treatment and antibiotic resistant pattern of colibacillosis and salmonellosis in broiler. J Biosci Agri Res 4: 67-73.

41. Azam M, Mohsin M, Rahman SU \& Saleemi MK (2019). Virulence-associated genes and antimicrobial resistance among avian pathogenic Escherichia coli from colibacillosis affected broilers in Pakistan. Trop Anim Health Prod 51: 1259-1265.

42. Bakhshi M, Bafghi MF, Astani A, Ranjbar VR, Zandi H \& Vakili M (2017). Antimicrobial resistance pattern of Escherichia coli isolated from chickens with colibacillosis in Yazd, Iran. J Food Quality Hazards Control (4): 74-78.

43. Sargeant JM, Bergevin MD, Churchill K, Dawkins K, Deb B, Dunn J, Logue CM, Novy A, O'Connnor AM, Reist M \& Winder CB (2019). The efficacy of antibiotics to control colibacillosis in broiler poultry: a systematic review. Anim Health Res Rev 20: 263-273.

44. Akbar H, Khan M, Khan AA, Khan MA, Shuaib M, Akbar SF, Manzoor S, Rehman IU, Ahmad S, Ali L, Khalid R \& Idress M (2009). Comparative efficacy of doxycycline and flumequine against experimentally induced colibacillosis in broiler chicks. J Vet Med Anim Health 1(2): 17-22.

45. John RG (1997). Fluoroquinolone use in poultry industry. Veterin Int 2: 25-30.

46. Anjum AD \& F Rizvi (1998). Use of second generation quinolones in poultry. Pak $J$ Biol Sci 1: 392-395. 